\title{
Heart block following stage 1 palliation of hypoplastic left heart syndrome
}

\author{
Douglas Y. Mah, MD, ${ }^{\text {a }}$ Henry Cheng, MD, ${ }^{\text {a }}$ Mark E. Alexander, MD, ${ }^{\text {a }}$ Lynn Sleeper, ScD, ${ }^{\mathrm{a}}$ \\ Jane W. Newburger, MD, ${ }^{a}$ Pedro J. del Nido, MD, ${ }^{b}$ Ravi R. Thiagarajan, MBBS, ${ }^{a}$ and \\ Satish K. Rajagopal, MD
}

\begin{abstract}
Objectives: Publicly available data from the Pediatric Heart Network's Single Ventricle Reconstruction Trial was analyzed to determine the prevalence, timing, risk factors for, and impact of second- and third-degree heart block (HB) on outcomes in patients who underwent stage 1 palliation (S1P) for hypoplastic left heart syndrome (HLHS).

Methods: The presence and date of onset of post-S1P HB occurring within the first year of life, potential risk factors for $\mathrm{HB}$, and factors known to predict poor outcomes after S1P were extracted. Multivariable logistic and Cox regression analyses were performed to identify risk factors for $\mathrm{HB}$ and to determine the effect of HB on 3-year transplantation-free survival.
\end{abstract}

Results: Among the 549 patients in the cohort, 33 (6\%) developed HB after S1P. The median interval between $\mathrm{S} 1 \mathrm{P}$ and $\mathrm{HB}$ was 8 days (interquartile range, 0-133 days). Regression analysis showed that tricuspid valve repair during S1P and obstruction of pulmonary venous drainage requiring pre-S1P intervention were independently associated with HB (adjusted odds ratio [aOR], 11.6, 95\% confidence interval [CI] 3.3-40; $P<.001$ and aOR, 5.1; 95\% CI, 1.3-20.6; $P=.02$, respectively). Transplantation-free survival at 3 years was lower for those with HB $(39 \%$ vs $65 \% ; P=.004)$. HB remained associated with transplantationfree survival after controlling for known risk factors (adjusted hazard ratio, 3.1; 95\% CI, 1.9-5.0; $P<.001)$. Nine children $(27 \%)$ had a pacemaker implanted, and 7 of these children $(78 \%)$ died or underwent heart transplantation.

Conclusions: $\mathrm{HB}$ after S1P is rare but heralds a poor outcome. Careful monitoring of these patients is recommended given their significantly increased risks of death and heart transplantation. (J Thorac Cardiovasc Surg 2016;152:189-94)

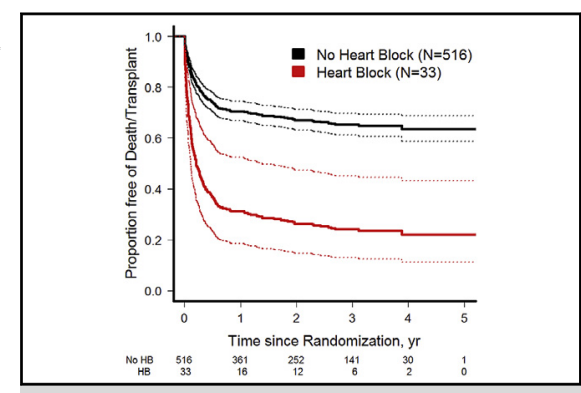

Transplantation-free survival curves in patients with and those without postoperative heart block.

Central Message

The development of heart block after stage I palliation heralds a poor outcome in patients with hypoplastic left heart syndrome.

Perspective

Patients with hypoplastic left heart syndrome who develop second- or third-degree hear block after stage I palliation are at high risk of dying or requiring heart transplantation. These patients may benefit from closer monitoring and earlier evaluation and listing for heart transplantation.

See Editorial Commentary page 195.
In the current era, 1 in 3 children with hypoplastic left syndrome (HLHS) and related variants undergoing stage 1 palliation (S1P) will die by age 3 years. ${ }^{1}$ Identification of early and specific risk factors portending a poor outcome is necessary to improve survival. Several risk factors for mortality have been identified, including birth weight $<2.5 \mathrm{~kg}$, moderate to severe preoperative tricuspid regurgitation, obstructed pulmonary venous drainage, presence of a

\footnotetext{
From the Departments of ${ }^{\mathrm{a} C}$ Cardiology and ${ }^{\mathrm{b}}$ Cardiovascular Surgery, Boston Children's Hospital and Harvard Medical School, Boston, Mass.

Received for publication Sept 15, 2015; revisions received March 25, 2016; accepted for publication March 31, 2016.

Address for reprints: Douglas Y. Mah, MD, Department of Cardiology, Boston Children's Hospital, 300 Longwood Ave, Boston, MA 02115 (E-mail: douglas. mah@cardio.chboston.org).

$0022-5223 / \$ 36.00$

Copyright (C) 2016 by The American Association for Thoracic Surgery

http://dx.doi.org/10.1016/j.jtcvs.2016.03.074
}

genetic syndrome, use of extracorporeal membrane oxygenation (ECMO) in the operating room, delayed sternal closure, anatomic diagnoses other than aortic stenosis/ mitral stenosis, and surgeon $\mathrm{S} 1 \mathrm{P}$ volume $\leq 5$ per year. ${ }^{1-3}$ A review of the data suggests that some important unidentified risk factors remain to be defined, however. The development of a detailed profile of the high-risk patient will allow for targeted interventions aimed at reducing the unacceptably high morbidity and mortality rates in these children.

Scanning this QR code will take you to the article title page.

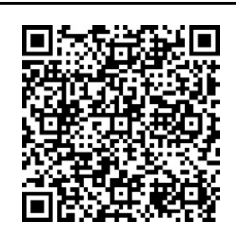




$$
\begin{aligned}
& \text { Abbreviations and Acronyms } \\
& \mathrm{aOR}=\text { adjusted odds ratio } \\
& \mathrm{AV}=\text { atrioventricular } \\
& \text { BDG = bidirectional Glenn } \\
& \mathrm{CI}=\text { confidence interval } \\
& \mathrm{CPR}=\text { cardiopulmonary resuscitation } \\
& \text { ECMO }=\text { extracorporeal membrane oxygenation } \\
& \mathrm{HB}=\text { heart block } \\
& \text { HLHS = hypoplastic left heart syndrome } \\
& \text { IQR = interquartile range } \\
& \text { S1P }=\text { stage } 1 \text { palliation } \\
& \text { S2P }=\text { stage } 2 \text { palliation } \\
& \text { SVR }=\text { Single Ventricle Reconstruction }
\end{aligned}
$$

Anecdotal observation of exceedingly poor survival among children with post-S1P atrioventricular (AV) node disturbance prompted us to hypothesize that postoperative heart block (HB) would be highly and independently associated with mortality. Despite the widespread use of S1P, remarkably little has been published about the fate of the $\mathrm{AV}$ node after S1P. Tabbutt et $\mathrm{al}^{3}$ reported that the presence of HB was not associated with mortality after S1P, but their analysis was restricted to patients who developed HB on postoperative day 0 , and follow-up was limited to initial hospital discharge or postoperative day 30 . We analyzed the publicly available Pediatric Heart Network's Single Ventricle Reconstruction (SVR) Trial database to determine the prevalence and timing of second- and third-degree HB in the first year after S1P, the risk factors for development of postsurgical $\mathrm{HB}$, and the relationship between $\mathrm{HB}$ and transplantation-free mortality.

\section{METHODS \\ Study Design}

The Pediatric Heart Network's SVR Trial is a multicenter, randomized trial comparing outcomes between alternative sources of pulmonary blood flow (right ventricle or aorta) during the Norwood procedure in patients with HLHS and related single right ventricle variants. The design of the SVR Trial has been published previously. ${ }^{4}$ The primary cohort consists of 549 patients. The primary outcome is freedom from death or transplantation at 12 months postrandomization using the intention-totreat principle. The inception cohort continues to be followed annually, with a minimum of 3 years of follow-up for all survivors. The Institutional Review Board of each participating center approved the SVR Trial, and parents/guardians of enrolled subjects provided informed consent. The Boston Children's Hospital Institutional Review Board approved the current analysis of the SVR Trial public database and waived the requirement for repeat informed consent.

\section{Data Collection and Definitions}

The National Heart, Lung, and Blood Institute's Pediatric Heart Network SVR Trial dataset was used in the present study. Data were downloaded from https://www.pediatricheartnetwork.com/pud_login.asp? study_id=SVR on January 20,2015. The presence and date of onset of post-S1P HB (either second- or third-degree) during the first year of life were extracted. HB was not characterized further (eg, second-degree vs third-degree, Mobitz I vs Mobitz II, duration). The primary outcome was transplantation-free survival using all available follow-up data (minimum of 3 years for transplantation-free survivors not lost to follow-up).

\section{Statistics}

SPSS version 19.0 (IBM, Armonk, NY), SAS version 9.3 (SAS Institute, Cary, NC), and R version 3.2.1 (R Project for Statistical Computing, Vienna, Austria) were used for statistical analyses. Summary statistics comparing patients with and without HB are reported as frequency (n) with proportion $(\%)$ or as median value with interquartile range (IQR). Wilcoxon's rank-sum test was used to compare the distributions of continuous variables by HB status. Fisher's exact test was used to compare the distributions of categorical variables by HB status.

Given the lack of preexisting evidence to guide modeling, all biologically plausible risk factors for the development of HB that were significant at a $P$ value $\leq .20$ on univariate analysis were used to develop a multivariable logistic regression model of post-S1P HB. No variable selection technique was used; that is, all variables were forced into the model. Multiple diagnostics were used to ensure model validity, including assessment of linearity of the logit using both Nagelkerke's $R^{2}$ statistic and the Hosmer and Lemeshow test, assessment of unduly influential cases using Cook's influence statistics, and assessment for multicollinearity among candidate predictors using the tolerance statistic and variance inflation factor. A Wald test $P$ value of $<.05$ was used to define significant covariates.

The independent relationship between post-S1P HB with onset up to 1 year and transplantation-free survival was assessed using proportional hazards modeling. A time-dependent HB indicator was fit in the model so that time before the onset of HB contributed to the hazard of death or transplantation associated with the absence of HB. Known risk factors for mortality and transplantation in this population were added to the model as covariates; no variable selection algorithm was used. For these additional factors, the assumption of proportional hazards was assessed graphically by examination of plots of $\ln (-\ln (S(t)))$ versus $\ln (t)$, where $\ln$ is the natural logarithm, $t$ is follow-up time, and $S(t)$ is the nonparametric estimate of freedom from death/transplantation. The estimated curves displaying freedom from death or transplantation by time-dependent $\mathrm{HB}$ status were obtained using the method of Thomas and Reyes. ${ }^{5}$ For all analyses, a $P$ value $\leq .05$ was considered statistically significant.

\section{RESULTS}

\section{Patient Characteristics}

Of the 549 patients who underwent S1P in the cohort, 33 $(6 \%)$ developed HB within the first year of life. The median interval between S1P and HB was 8 days (IQR, 0-133 days). $\mathrm{HB}$ onset was temporally associated with cardiac surgery (S1P or stage 2 palliation [S2P]) in the majority of cases: $58 \%(\mathrm{n}=19)$ on the day of surgery (13 on the day of S1P and 6 on the day of S2P) and $76 \%(n=25)$ within 7 days of surgery (16 within 7 days of S1P and 9 within 7 days of S2P).

\section{Risk Factors for HB}

Potential risk factors for the development of HB are summarized in Table 1. A multivariable logistic regression model including all 549 patients demonstrated that tricuspid valve repair during S1P and obstruction of pulmonary venous drainage requiring pre-S1P intervention were independently associated with HB (adjusted odds ratio [aOR], 11.6; 95\% confidence interval [CI], 3.3-40; 
TABLE 1. Univariable analysis of factors associated with $\mathrm{HB}$ after S1P $(\mathrm{n}=549)$

\begin{tabular}{|c|c|c|c|}
\hline Variable & HB $(\mathbf{n}=33)$ & No HB $(n=516)$ & $P$ value \\
\hline \multicolumn{4}{|l|}{ Pre-S1P variables } \\
\hline Age at S1P, d, median (IQR) & $5(4-8)$ & $6(4-8)$ & .33 \\
\hline Female sex, $\mathrm{n}(\%)$ & $13(39)$ & $196(38)$ & .86 \\
\hline Preterm (<37 wk gestation), n $(\%)$ & $6(18)$ & $58(11)$ & .26 \\
\hline Apgar score at 1 min, median (IQR) & $8(7-9)$ & $8(7-9)$ & .57 \\
\hline Apgar score at 5 min, median (IQR) & $9(8-9)$ & $9(8-9)$ & .76 \\
\hline Birth weight, kg, median (IQR) & $3.2(2.8-3.5)$ & $3.1(2.8-3.5)$ & .81 \\
\hline Birth weight $<2.5 \mathrm{~kg}, \mathrm{n}(\%)$ & $5(15)$ & $71(14)$ & .80 \\
\hline Prenatal diagnosis, $\mathrm{n}(\%)$ & $25(76)$ & $395(77)$ & 1.00 \\
\hline $\mathrm{CO}_{2}$ added to inspired gas, $\mathrm{n}(\%)$ & $2(6)$ & $14(3)$ & .25 \\
\hline $\mathrm{N}_{2}$ added to inspired gas, $\mathrm{n}(\%)$ & $3(9)$ & $69(13)$ & .60 \\
\hline Lactate checked, n (\%) & $24(75)$ & $424(83)$ & .24 \\
\hline Highest lactate value, $\mathrm{mmol} / \mathrm{L}$, median (IQR) & $3.4(2.5-4.9)$ & $3.1(2.8-3.5)$ & .30 \\
\hline Intubated at any point, $\mathrm{n}(\%)$ & $15(46)$ & $248(48)$ & .45 \\
\hline Interventional catheterization, $\mathrm{n}(\%)$ & $3(9)$ & $25(5)$ & .23 \\
\hline Cardiac surgical intervention, $\mathrm{n}(\%)$ & $1(3)$ & $4(1)$ & .27 \\
\hline Number of preoperative complications, $\mathrm{n}(\%)$ & & & .13 \\
\hline 0 & $22(67)$ & $374(73)$ & \\
\hline 1 & $8(24)$ & $68(13)$ & \\
\hline 2 & $3(9)$ & $35(7)$ & \\
\hline$\geq 3$ & $0(0)$ & $39(8)$ & \\
\hline HB, second- or third-degree, n (\%) & $0(0)$ & $2(0.4)$ & 1.0 \\
\hline Anatomic variables & $(\mathrm{n}=33)$ & $(\mathrm{n}=516)$ & \\
\hline Ascending aorta diameter measured during S1P, mm, median (IQR) & $2.5(1.9-3.9)$ & $2.5(2.2-3.8)$ & .66 \\
\hline Classic aortic arch reconstruction, $\mathrm{n}(\%)$ & $29(88)$ & $450(88 \%)$ & .97 \\
\hline Anatomic subtype, $\mathrm{n}(\%)$ & & & .99 \\
\hline HLHS or critical aortic stenosis & $29(88)$ & $450(87)$ & \\
\hline Single right ventricle with systemic outflow obstruction & $1(3)$ & $15(3)$ & \\
\hline Right dominant AV canal with systemic outflow obstruction & $2(6)$ & $29(6)$ & \\
\hline $\begin{array}{l}\text { Straddling mitral valve (or other single right ventricle lesions) } \\
\text { with LV hypoplasia with outflow obstruction }\end{array}$ & $1(3)$ & $15(3)$ & \\
\hline Aortic valve atresia, $\mathrm{n}(\%)$ & $23(70)$ & $320(62)$ & .46 \\
\hline HLHS (mitral stenosis, aortic stenosis), n (\%) & $4(12)$ & $106(21)$ & .37 \\
\hline Tricuspid regurgitation (moderate or severe), $\mathrm{n}(\%)$ & $6(18)$ & $59(11)$ & .26 \\
\hline Obstructed pulmonary venous drainage (requiring pre-S1P intervention), n (\%) & $3(9)$ & $17(3)$ & .10 \\
\hline S1P surgical variables & $(\mathrm{n}=33)$ & $(\mathrm{n}=516)$ & \\
\hline Surgeon S1P volume $<6$ per y, n $(\%)$ & $5(15)$ & $103(20)$ & .65 \\
\hline Center S1P volume $>20$ per $\mathrm{y}, \mathrm{n}(\%)$ & $24(73)$ & $323(63)$ & .27 \\
\hline Cardiopulmonary bypass time, min, median (IQR) & $127(83-180)$ & $140(106-170)$ & .54 \\
\hline Cross-clamp time, min, median (IQR) & $57(42-76)$ & $53(40-67)$ & .32 \\
\hline Deep hypothermic cardiac arrest used for $>5 \mathrm{~min}, \mathrm{n}(\%)$ & $33(100)$ & $479(93)$ & .16 \\
\hline Steroids administered on cardiopulmonary bypass, $\mathrm{n}(\%)$ & $32(97)$ & $466(90)$ & .35 \\
\hline Tricuspid valvuloplasty during S1P, n (\%) & $5(15)$ & $7(1.4)$ & $<.01$ \\
\hline Shunt type, $\mathrm{n}(\%)$ & & & .35 \\
\hline Blalock-Taussig & $14(42)$ & $253(49)$ & \\
\hline Sano & $18(55)$ & $259(50)$ & \\
\hline Blalock-Taussig and Sano & $1(3)$ & $5(1)$ & \\
\hline Intraoperative shunt crossover, $\mathrm{n}(\%)$ & $3(9)$ & $44(9)$ & .76 \\
\hline Repair of partial or total anomalous venous return, $\mathrm{n}(\%)$ & $1(3)$ & $5(1)$ & .31 \\
\hline Sternum left open, $\mathrm{n}(\%)$ & $24(73)$ & $393(76)$ & .68 \\
\hline ECMO, failure to wean from cardiopulmonary bypass, n (\%) & $4(12)$ & $31(6)$ & .15 \\
\hline $\mathrm{S} 2 \mathrm{P}$ surgical variables & $(\mathrm{n}=12)$ & $(\mathrm{n}=388)$ & \\
\hline Pre-S2P interventional catheterization, n (\%) & $5(42)$ & $118(30)$ & .53 \\
\hline Elective S2P, n (\%) & $7(58)$ & $256(66)$ & .55 \\
\hline Atrial septectomy, n (\%) & $0(0)$ & $10(3)$ & 1.00 \\
\hline
\end{tabular}


TABLE 1. Continued

\begin{tabular}{|c|c|c|c|}
\hline Variable & HB $(\mathbf{n}=33)$ & No HB $(n=516)$ & $P$ value \\
\hline PAPVR or TAPVR repair, $n(\%)$ & $0(0)$ & $7(2)$ & 1.00 \\
\hline Cardiopulmonary bypass time, min, median $(\mathrm{IQR})(\mathrm{n}=391)$ & $75(59-113)$ & $86(65-126)$ & .37 \\
\hline Receipt of steroids, $n(\%)(n=394)$ & $9(75)$ & $231(61)$ & .38 \\
\hline Tricuspid valvuloplasty at S2P, n (\%) & $5(42)$ & $21(5)$ & $<.01$ \\
\hline Tricuspid valvuloplasty at S1P, n (\%) & $2(17)$ & $6(2)$ & .02 \\
\hline Redo tricuspid valvuloplasty at S2P, n (\%) & $1(8)$ & $1(0.3)$ & .06 \\
\hline Cavopulmonary connection type, $\mathrm{n}(\%)$ & & & .93 \\
\hline Bidirectional (left or right) & $7(58)$ & $245(63)$ & \\
\hline Hemi-Fontan (left or right) & $4(33)$ & $92(24)$ & \\
\hline Bidirectional (bilateral) & $1(8)$ & $42(11)$ & \\
\hline Kawashima & $0(0)$ & $6(2)$ & \\
\hline Unidirectional (left or right) & $0(0)$ & $3(1)$ & \\
\hline
\end{tabular}

$\overline{H B}$, Heart block; $S I P$, stage 1 palliation; $I Q R$, interquartile range; $H L H S$, hypoplastic left heart syndrome; $A V$, atrioventricular; $L V$, left ventricular; $E C M O$, extracorporeal membrane oxygenation; $S 2 P$, stage 2 palliation; $P A P V R$, partial anomalous pulmonary venous return; TAPVR, total anomalous pulmonary venous return.

$P<.001$ and aOR, $5.1 ; 95 \% \mathrm{CI}, 1.3-20.6 ; P=.02$, respectively). Preoperative medical condition, weight, HLHS subtype, ascending aorta diameter, preoperative interventional catheterization, intraoperative surgical support time, circulatory arrest use, shunt type, and surgeon S1P volume were not associated with HB. A second logistic regression model, contingent on survival to S2P $(n=400)$, identified tricuspid valve repair at $\mathrm{S} 2 \mathrm{P}$ or at $\mathrm{S} 1 \mathrm{P}$ as independent risk factors for new-onset $\mathrm{HB}$ (aOR, 10.8; 95\% CI, 3.0-38.7; $P<.001$ and aOR, 8.6; 95\% CI, 1.3-59.7; $P=.03$, respectively).

\section{Outcomes and Transplantation-Free Survival in Children With HB}

Transplantation-free survival for patients with and without HB is summarized in Figure 1. Survival at 3 years was lower for the children with HB than for those without HB ( $39 \%$ vs $65 \% ; P=.004)$. The median interval between HB onset and death or transplantation was 104 days (IQR, 49-254 days). Of 17 surviving patients, 13 received S2P and 4 underwent transplantation ( 1 after S2P). Of the 16 patients who died, 8 succumbed before S2P (1 after transplantation) and 8 died after S2P (1 after transplantation). The adjudicated cause of death was cardiovascular in 6 patients, infectious in 5 patients, unknown in 3 patients, and surgical complications in 2 patients. Further details regarding the mechanism of cardiovascular death were not publicly available.

To determine whether HB was an independent predictor of death or transplantation, it was added to a proportional hazards model containing previously identified risk factors for poor outcomes (Table 2). This analysis demonstrated that HB remained associated with transplantation-free survival after controlling for known risk factors (adjusted hazard ratio, $3.1 ; 95 \% \mathrm{CI}, 1.9-5.0 ; P<.001)$.

Nine of the 33 children with HB $(27 \%)$ had a pacemaker implanted. Permanent pacing did not appear to effect the rate of death or transplantation in those with $\mathrm{HB}(78 \%$ vs $54 \% ; P=.26)$. The pacing modality was epicardial dual chamber in 5 patients, epicardial ventricular in 2 patients, and unclear in 2 patients.

\section{DISCUSSION}

Despite advances in the management of patients with HLHS, one-third of these children will die or require heart transplantation by age 3 years. ${ }^{1}$ Numerous studies have evaluated strategies to optimize the care of this complex cohort, and high-risk patients have been identified. ${ }^{6-10}$ The present study is the first to identify the development of second- or third-degree HB as a significant predictor of

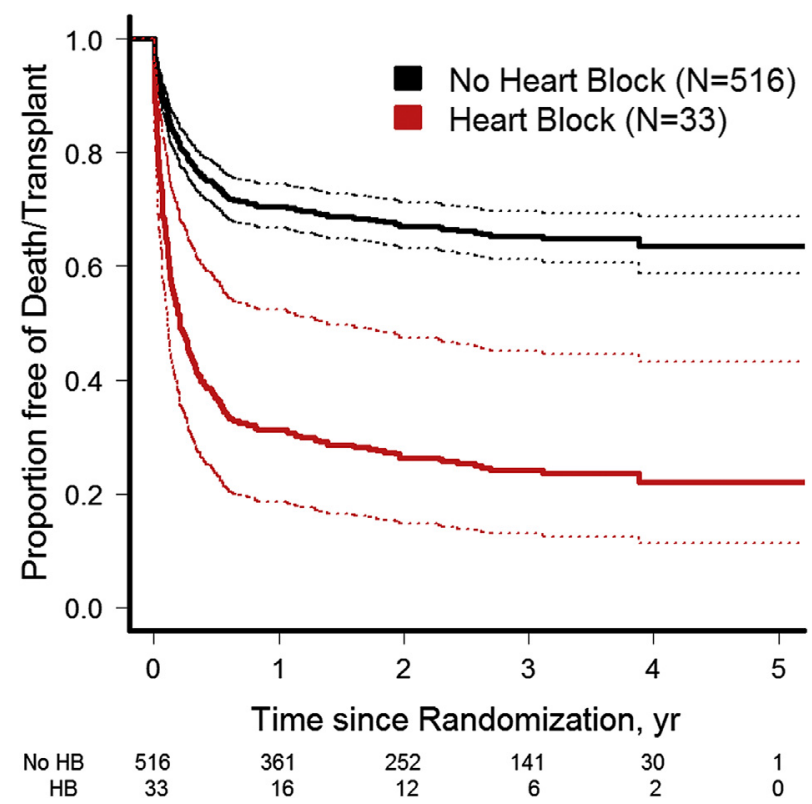

FIGURE 1. Transplantation-free survival curves and $95 \%$ pointwise confidence bands in patients with or without postoperative $\mathrm{HB}$ in the first year after S1P $(P<.001)$. The estimates were obtained using a time-dependent indicator for HB status. The numbers at risk by year are also shown; however, owing to the time-dependent nature of the grouping, the 33 patients with $\mathrm{HB}$ contributed some follow-up time to the no-HB group in the first year. The data are truncated at 5 years. 
TABLE 2. Multivariable Cox proportional hazards analysis of predictors of death or transplantation after S1P palliation of HLHS and related variants $(n=549)$

\begin{tabular}{lccr}
\hline \multicolumn{1}{c}{ Variable } & $\begin{array}{c}\text { Adjusted } \\
\text { HR }\end{array}$ & $\mathbf{9 5 \%}$ CI & $\begin{array}{c}\boldsymbol{P} \\
\text { value }\end{array}$ \\
\hline HB & 3.1 & $1.9-5.0$ & $<.001$ \\
Sternum left open & 2.0 & $1.4-3$ & $<.001$ \\
Genetic syndrome & & & $<.001$ \\
$\quad$ No & Reference & & \\
$\quad$ Yes & 2.8 & $1.5-5.2$ & $<.001$ \\
$\quad$ Unknown & 3.5 & $2.6-4.7$ & $<.001$ \\
Surgeon S1P volume $<6$ per y & 1.6 & $1.1-2.2$ & .009 \\
Aortic stenosis and mitral stenosis & 0.6 & $0.4-0.9$ & .008 \\
Need for intraoperative ECMO & 3.1 & $2.0-4.9$ & $<.001$ \\
Birth weight $<2.5$ kg & 2.1 & $1.5-3.0$ & $<.001$ \\
Tricuspid valvuloplasty & 2.3 & $1.1-5.0$ & .034 \\
$\quad$ at Norwood procedure & & & \\
Obstructed pulmonary venous drainage & 2.4 & $1.3-4.3$ & .003 \\
$\quad$ (requiring pre-S1P intervention) & & & \\
\hline
\end{tabular}

$H R$, Hazard ratio; $C I$, confidence interval; $H B$, heart block; $S I P$, stage 1 palliation; $E C M O$, extracorporeal membrane oxygenation.

poor outcomes in children undergoing S1P $(61 \%$ dead or transplanted during the follow-up period). In addition, our data suggest that attempted repair of the tricuspid valve at either S1P or S2P is a risk factor for the development of postoperative HB. Although the incidence of postsurgical HB in patients with HLHS was relatively low $(6 \%)$, when present it is as potently associated with adverse outcomes as is the need for ECMO to separate from cardiopulmonary bypass after S1P, preoperative obstruction of pulmonary venous drainage return requiring pre-S1P intervention, and the presence of an underlying genetic syndrome.

The incidence of $\mathrm{HB}$ in this patient population is similar to that of other complex heart lesions. ${ }^{11}$ Previous studies have documented the relationships between $\mathrm{HB}$ and tetralogy of Fallot, septal defects, and L-looped transposition of the great arteries ${ }^{11-13}$; however, to our knowledge, this is the first study to demonstrate an association between $\mathrm{HB}$ and tricuspid valve surgery during surgical palliation. This finding comes as no surprise, given the close relationship of the $\mathrm{AV}$ node to the tricuspid valve annulus, especially in the infant heart. As such, in the rare circumstance of tricuspid regurgitation requiring surgical address during palliation in these patients, particular attention should be given to defining the anatomy of Koch's triangle, thereby minimizing the risk to the conduction system.

The exact nature of the relationship between HB and failure of staged palliation is not clear from this study; however, placement of an epicardial pacing system failed to rescue any of these patients. This finding is in keeping with previous studies demonstrating an association between worsening single ventricle function and pacing. ${ }^{14-16} \mathrm{An}$ alternative hypothesis to explain the relationship between
HB and poor outcomes in children with HLHS is that the disturbance in $\mathrm{AV}$ node function is a manifestation of coronary insufficiency. Myocardial ischemia is an established cause of mortality after staged palliation, most commonly related to precoronary obstruction from a suboptimal Damus-Kaye-Stansel anastomosis and/or excessive pulmonary blood flow, resulting in coronary hypoperfusion. ${ }^{17}$

The data from this study suggest that children who develop second- or third-degree HB after staged palliation are at particularly high risk of dying before Fontan completion despite pacemaker placement. Although the reason why all of the patients with $\mathrm{HB}$ did not have a pacemaker implanted could not be determined from this database (ie, resolution of conduction disturbance vs HB not meeting indications for pacing), it is clear that postoperative $\mathrm{HB}$ represents a major risk factor for a poor outcome. At a minimum, these at-risk patients should be enrolled in an intensive interstage home monitoring program. If future studies of other cohorts of children undergoing staged palliation corroborate these findings, then more aggressive diagnostic and management strategies, (eg, cardiac catheterization for hemodynamics, evaluation of the Damus-Kaye-Stansel anastomosis, coronary angiography) and earlier evaluation and listing for heart transplantation can be explored for those who develop postoperative HB.

The results of this study should be interpreted with an understanding of its limitations. Because the Pediatric Heart Network's SVR Trial was not designed to characterize the fate of the AV node after staged palliation, many important variables were not recorded, such as the exact type of $\mathrm{HB}$ (eg, Mobitz II vs third-degree), the date of HB resolution (if any), and details of the tricuspid valve intervention (eg, isolated annuloplasty vs valvuloplasty). Considering that the development of postoperative HB was not the primary focus of the trial, it is possible that cases of temporary $\mathrm{HB}$ were missed, resulting in an underestimation of its true incidence. As in all epidemiologic analyses involving regression modeling, potentially important confounders of the relationships between $\mathrm{HB}$ and death or transplantation might not have been considered.

In conclusion, the risk of developing HB in patients with HLHS after the Norwood procedure is relatively low and is associated with concomitant tricuspid valve surgery. Though rare, the presence of AV nodal injury in the postS1P period portends a poor outcome. These children should be carefully monitored, given the significantly increased risk of death or transplantation in this tenuous subgroup of patients with HLHS.

\section{Conflict of Interest Statement}

L.S. and J.W.N. have received grant support from the National Institutes of Health/National Heart, Lung, and 
Blood Institute. R.R.T. is a member of the Clinical Trials Adjudication Committee for Bristol Myers Squibb. All other authors have nothing to disclose with regard to commercial support.

\section{References}

1. Newburger JW, Sleeper LA, Frommelt PC, Pearson GD, Mahle WT, Chen S, et al. Transplantation-free survival and interventions at 3 years in the Single Ventricle Reconstruction Trial. Circulation. 2014;129:2013-20.

2. Ghanayem NS, Allen KR, Tabbutt S, Atz AM, Clabby ML, Cooper DS, et al. Interstage mortality after the Norwood procedure: results of the multicenter Single Ventricle Reconstruction Trial. J Thorac Cardiovasc Surg. 2012;144: 896-906.

3. Tabbutt S, Ghanayem N, Ravishankar C, Sleeper LA, Cooper DS, Frank DU, et al. Risk factors for hospital morbidity and mortality after the Norwood procedure: a report from the Pediatric Heart Network Single Ventricle Reconstruction Trial. J Thorac Cardiovasc Surg. 2012;144:882-95.

4. Ohye RG, Gaynor JW, Ghanayem NS, Goldberg CS, Laussen PC, Frommelt PC, et al. Design and rationale of a randomized trial comparing the Blalock-Taussig and right ventricle-pulmonary artery shunts in the Norwood procedure. J Thorac Cardiovasc Surg. 2008;136:968-75.

5. Thomas L, Reyes EM. Tutorial: survival estimation for Cox regression models with time-varying coefficients using SAS and R. J Stat Software. 2014;61:CS1.

6. Alsoufi B, McCracken C, Ehrlich A, Mahle WT, Kogon B, Border W, et al. Single ventricle palliation in low weight patients is associated with worse early and midterm outcomes. Ann Thorac Surg. 2015;99:668-76.

7. Alsoufi B, Mori M, Gillespie S, Schlosser B, Slesnick T, Kogon B, et al. Impact of patient characteristics and anatomy on results of Norwood operation for hypoplastic left heart syndrome. Ann Thorac Surg. 2015;100:591-8.

8. Karamlou T, Overman D, Hill KD, Wallace A, Pasquali SK, Jacobs JP, et al. Stage 1 hybrid palliation for hypoplastic left heart syndrome: assessment of contemporary patterns of use: an analysis of the Society of Thoracic Surgeons congenital heart surgery database. J Thorac Cardiovasc Surg. 2015;149: 195-201. 202.e1.
9. Nathan M, Sleeper LA, Ohye RG, Frommelt PC, Caldarone CA, Tweddell JS, et al. Technical performance score is associated with outcomes after the Norwood procedure. J Thorac Cardiovasc Surg. 2014;148:2208-13. 2214.e1-6.

10. Sata S, Sinzobahamvya N, Arenz C, Zartner P, Asfour B, Hraska V. Restrictive atrial septum defect becomes a risk factor for Norwood palliation of hypoplastic left heart syndrome only when it is combined with mitral or aortic atresia. Thorac Cardiovasc Surg. 2015;63:354-9.

11. Weindling SN, Saul JP, Gamble WJ, Mayer JE, Wessel D, Walsh EP. Duration of complete atrioventricular block after congenital heart disease surgery. Am J Cardiol. 1998;82:525-7.

12. Aziz PF, Serwer GA, Bradley DJ, LaPage MJ, Hirsch JC, Bove EL, et al. Pattern of recovery for transient complete heart block after open heart surgery for congenital heart disease: duration alone predicts risk of late complete heart block. Pediatr Cardiol. 2013;34:999-1005.

13. Anderson JB, Czosek RJ, Knilans TK, Meganathan K, Heaton P. Postoperative heart block in children with common forms of congenital heart disease: results from the KID database. J Cardiovasc Electrophysiol. 2012;23:1349-54.

14. Fishberger SB, Wernovsky G, Gentles TL, Gamble WJ, Gauvreau K, Burnett J, et al. Long-term outcome in patients with pacemakers following the Fontan operation. Am J Cardiol. 1996;77:887-9.

15. Williams RV, Travison T, Kaltman JR, Cecchin F, Colan SD, Idriss SF, et al. Comparison of Fontan survivors with and without pacemakers: a report from the Pediatric Heart Network Fontan Cross-Sectional Study. Congenit Heart Dis. 2013;8:32-9.

16. Gentles TL, Mayer JE Jr, Gauvreau K, Newburger JW, Lock JE, Kupferschmid JP, et al. Fontan operation in five hundred consecutive patients: factors influencing early and late outcome. J Thorac Cardiovasc Surg. 1997; 114:376-91.

17. Bartram U, Grünenfelder J, Van Praagh R. Causes of death after the modified Norwood procedure: a study of 122 postmortem cases. Ann Thorac Surg. 1997;64:1795-802.

Key Words: heart block, hypoplastic left heart syndrome, mortality, stage I palliation, tricuspid valvuloplasty 